\title{
A Case of Factitious Hypoglycemia Induced by Self-Administration of Sulfonylurea
}

\author{
-With Special Reference to Differentiation from Insulinoma-
}

\author{
Kenji Shima, M D, Ryoichi Tanaka, M D, \\ Jiro Nakamura, M D, Yoshiaki Okada, M D \\ and Yuichi Kumahara, MD
}

\begin{abstract}
A 23-year-old nurse had sulfonylurea-induced factitious hypoglycemia. She demonstrated the high plasma insulin level relative to blood glucose and the positive prolonged fasting test. The response of plasma insulin to glucagon and tolbutamide was not typical of insulinoma. Furthermore, plasma C-peptide concentration was suppressed following the injection of insulin. These findings, together with no demonstrable radiologic evidence of an insulin secreting tumor prompted us to measure the serum concentration of sulfonylurea though she adamantly denied taking hypoglycemic drug. The presence of a significant amount of sulfonylurea, $13.3 \mathrm{mg} / \mathrm{dl}$ equivalent to tolbutamide, in her serum assured our suspicion of factitious hypoglycemia. The differential diagnosis between insulinoma and other causes of hypoglycemia is discussed, specially emphasizing the suppressability of plasma C-peptide concentration following the injection of insulin for ruling out the former.
\end{abstract}

Key Words : Insulinoma, Hypoglycemic drug, Insulin, Prolonged fasting test, Glucagon, Tolbutamide, G-peptide.

Hypoglycemia may be associated with a number of disease entities. When absolute or relative hyperinsulinemia is demonstrated, insulinoma must be suspected. Factitious hypoglycemia caused by sulfonylurea agents or insulin shows clinical and biochemical findings similar to those of insulinoma. Therefore, if the patient tries to keep having taken these agents secret, the diagnosis is misled, resulting in needless laparotomy for suspected insulinoma. ${ }^{1-3)}$

Recently, we experienced a case with hypoglycemia of which etiology was difficult to determine, though the presence of an insulin-secreting tumor had been initially suspected on the basis of her clinical and biochemical findings. Finally, her hypoglycemia was diagnosed as factitious since blood determination revealed a high con- centration of sulfonylurea.

In this report, we describe an insulin suppression test, assessed by measuring plasma C-peptide levels during insulininduced hypolycemia,, ${ }^{4,5)}$ for differentiating sulfonylurea intoxication from an insulinoma. In addition, the clinical course of the patient is presented, to contribute to paying attention to this state.

\section{METHODS}

All tests were done after an overnight fast. Oral glucose tolerance test: $100 \mathrm{~g}$ of glucose was given orally and blood samples were obtained at $0,30,60,90,120$ and 180 minutes for determinations of blood glucose, plasma immunoreactive insulin (IRI) and C-peptide immunoreactivity (CPR). Glucagon test: $1 \mathrm{mg}$ of glucagon (NOVO, Den-

From Department of Medicine and Geriatrics, Osaka University Medical School, Osaka.

Received for publication August 15, 1977.

Reprints request to: Kenji Shima, Department of Medicine and Geriatrics, Osaka University Medical School, 1-50, 1-chome Fukushima, Fukushima-ku, Osaka, 553, Japan. 
mark) dissolved in $20 \mathrm{ml}$ of saline was injected intravenously in $3 \mathrm{~min}$. Blood samples were taken at $0,2,5,10,15,30,45$ and 60 min, regarding the midpoint of the injection as zero time. Blood glucose and plasma IRI levels were measured. Tolbutamide test: $1 \mathrm{~g}$ of Na-tolbutamide (Höchst Japan) dissolved in $20 \mathrm{ml}$ of saline was injected intravenously. Blood samples were taken at $0,30,45,60,90$, and $120 \mathrm{~min}$ for determination of blood glucose and plasma IRI. Insulin tolerance test: After two basal blood samples were obtained, $0.1 \mathrm{U}$ per $\mathrm{kg}$ body weight of Monocomponent Actrapid Insulin" (pork insulin, NOVO, Denmark) was injected intravenously as a bolus. Additional blood specimens were taken from a contralateral cubital vein catheter connected to a three way stopcock, kept patent with an infusion of saline at 10, 20, $30,45,60,90$ and $120 \mathrm{~min}$ after the injection. Blood glucose, plasma CPR, immunoreactive glucagon (IRG), cortisol and HGH levels were measured. Urine samples were collected for a two-hour period before and after the injection of insulin for determination of catecholamine content. Arginine test: $30 \mathrm{~g}$ of L-arginine hydrochloride diluted in $300 \mathrm{ml}$ of water was infused at a constant rate for $30 \mathrm{~min}$ in the cubital vein. Blood was taken at 15 and 0 min before the infusion and at 10,20,30,45, 60 and 90 min after the infusion was begun. Blood glucose, plasma GPR and IRG levels were determined.

Blood glucose was determined by Autoanalyzer. IRG was measured by the radioimmunoassay method described previously using antiserum specific for pancreatic glucagon. ${ }^{6)}$ Plasma IRI, CPR, cortisol, $\mathrm{HGH}$ and urinary catecholamine were measured using the respective kits (IRI: Pharmacia, Sweden. CPR: Daiichi Radioisotope Labs., LTD., Tokyo. cortisol: Eiken Immunochemical Labs., LTD., Tokyo. HGH : Dainabot Radioisotope Labs., LTD., Tokyo. catecholamine: Oxford Labs., Calif. U.S.A.) Blood sulfonylurea was determined by colorimetric method. ${ }^{\text {? }}$

\section{CASE REPORT}

An unmarried woman, a nurse aged 23, was admitted to the Osaka University Hospital on Feb. 22, 1977, complaining of hypoglycemia with an attack of unconsciousness. The patient had been well until January, 1976, when she began to experience anorexia, amenorrhea and loss of weight. Studies revealed no abnormality in the thyroid, pituitary and adrenal functions. A minor tranquilizer was prescribed for anorexia nervosa, resulting in slight improvement of this disorder. She gained weight to $40 \mathrm{~kg}$ by January 1977. Then she began to feel unusually hungry and eat between meals, otherwise she would experience spells of weakness and giddiness. These episodes usually occurred late in the afternoon: they were relieved by eating. On Feb. 9, she was admitted to a hospital for unconsciousness. Blood glucose was 31 $\mathrm{mg} / \mathrm{dl}$.

Because of the hypoglycemic value, she was referred to our hospital for further evaluation. A careful history led to the denial of the use of any hypoglycemic agents at any time. There was no family history of diabetes. No abnormalities were found on physical examination except for the liver palpable one finger-breath below the costal margin. Her weight was $40 \mathrm{~kg}$ and height $157 \mathrm{~cm}$.

Routine laboratory tests (hemoglobin, hematocrit, leucocyte count, urinalysis, electrolytes, total protein, albumin, serum GOT, GPT, bilirubin, and alkaline phosphatase) were within normal limits. The urinary excretion of 17-ketosteroids and 17-hydroxycorticosteroids was within normal limits as well. $\mathrm{T}_{3}, \mathrm{~T}_{4}$ and $\mathrm{RT}_{3} \mathrm{U}$ were $68 \mathrm{ng} / \mathrm{dl}, 8.3 \mu \mathrm{g} / \mathrm{dl}$ and $27 \%$, respectively. Electrocardiogram, liver and pancreas scan with ${ }^{76}$ Se-selenomethionin, and $\mathrm{x}$-rays of the chest, abdomen, and upper gastrointestinal tract were unremarkable. The result of a glucose tolerance test performed on the day subsequent to her admission is presented in Table 1. The low blood sugar levels were demonstrated at any periods 
Table 1. Ghanges in blood sugar, plasma IRI and CPR concentrations during $100 \mathrm{~g}$ oral glucose tolerance test.

\begin{tabular}{lllllllll} 
& \multicolumn{8}{c}{ minute after oral qlucose } \\
\cline { 2 - 8 } & 0 & 30 & 60 & 90 & 120 & 180 & 240 & 300 \\
\hline BS (mg/dl) & 25 & 45 & 30 & 50 & 35 & 45 & 20 & 25 \\
IRI $(\mu \mathrm{U} / \mathrm{ml})$ & 25 & 34 & 28 & 40 & 30 & 20 & 16 & 15 \\
$\mathrm{CPR}(\mathrm{ng} / \mathrm{mI})$ & 3.5 & 6.3 & 5.9 & 7.7 & 6.6 & 5.9 & 4.4 & 3.4 \\
\hline
\end{tabular}

during the test. The plasma IRI and CPR levels were high relative to the corresponding blood sugar. BS/IRI at the fasting state was 1.0 which was the value compatible with a criterion for a firm diagnosis of insulinoma according to Shatney et al. ${ }^{8)}$ Following completion of the 5-hr oral glucose tolerance test, the patient was kept fasting until 3:10 p.m., about 9 hours after an oral administration of glucose, when she was semicomatose, and her blood sugar level registered $19 \mathrm{mg} / \mathrm{dl}$.

These findings strongly suggested the existence of a functioning islet-cell tumor. To assure the possibility of insulinoma, the provocative tests, routinely performed for diagnosing this disorder hitherto, were done. The results of the tests are shown in

Table 2. Changes in blood sugar and plasma IRI concentrations during glucagon and tolbutamide tests.

\begin{tabular}{|c|c|c|c|c|c|c|c|c|c|c|c|}
\hline & \multicolumn{10}{|c|}{ minute after injection of aqents } \\
\hline & & 0 & 2 & 5 & 10 & 15 & 30 & 45 & 60 & 90 & 120 \\
\hline \multirow[t]{2}{*}{$\begin{array}{l}\text { glucagon } \\
\text { (Img, iv) }\end{array}$} & BS $(\mathrm{mg} / \mathrm{dl})$ & 80 & 80 & 85 & 110 & 120 & 85 & 75 & 60 & & \\
\hline & IRI $(\mu \mathrm{U} / \mathrm{mI})$ & 17 & 17 & 18 & 45 & 32 & 13 & 3 & 2 & & \\
\hline \multirow[t]{2}{*}{$\begin{array}{l}\text { tolbutamic } \\
(1 \mathrm{~g}, \text { iv) }\end{array}$} & ${ }_{\text {BS }}$ (mg/dl) & 77 & & & & & 32 & 23 & 39 & 54 & 70 \\
\hline & $\operatorname{IRI}(\mu \mathrm{U} / \mathrm{ml})$ & 8 & & & & & 12 & 8 & 5 & 1 & 1 \\
\hline
\end{tabular}

Table 2. Neither glucagon nor tolbutamide elicited the exaggerated plasma IRI response which was reported to occur in 70$80 \%$ of the patients with insulinoma. ${ }^{9)}$ The blood sugar responses to glucagon and tolbutamide were within normal range. As the most reliable mean of documenting inappropriate insulin release in a patient with insulinoma, insulin suppression test which has been recently developed ${ }^{10,11)}$ was performed. After the injection of exogenous insulin, serum GPR was measured to moni-

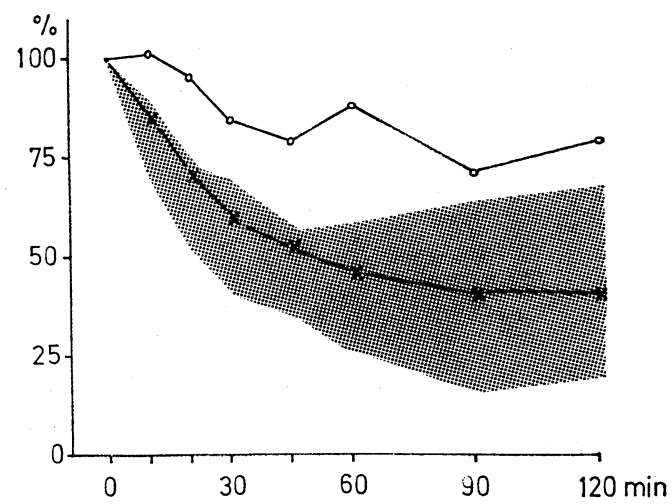

Fig. 1. Per cent decrease of plasma CPR level following insulin injection

$\times \longrightarrow \times$ : present case

$\bigcirc-\bigcirc$ : insulinoma experienced by one (K. S.) of us

Shaded area represents normal range

$($ Mean $\pm 2 \mathrm{SD})$

ter endogenous insulin secretion. The result is shown in Fig. 1. Plasma CPR level declined normally in accordance with decrease in blood sugar level. This is in sharp contrast with a small decrease in plasma GPR level in a patient with insulinoma which was confirmed surgically. A selective celiac angiography revealed no evidence of a tumor in the pancreas. Other endocrine functions apparently related to homeostasis of the blood sugar concentration were normal as shown in Table 3 and 4 .

Table 3. Responses to intravenous injection of insulin $(0.1 \mathrm{U} / \mathrm{kg})$ and infusion of arginine (30 g over 30 minutes).

\begin{tabular}{|c|c|c|c|c|c|c|c|c|c|c|}
\hline & \multicolumn{9}{|c|}{ minute after administration of agents } \\
\hline & & -15 & 0 & 10 & 20 & 30 & 45 & 60 & 90 & 120 \\
\hline \multirow[t]{5}{*}{ ITT } & BS (mg/dl) & 83 & 78 & 31 & 27 & 33 & 29 & 32 & 39 & 40 \\
\hline & $\mathrm{CPR}(\mathrm{ng} / \mathrm{ml})$ & 1.5 & 1.4 & 1.3 & 1.1 & 0.9 & 0.8 & 0.7 & 0.6 & 0.6 \\
\hline & $\mathrm{GH}(\mathrm{ng} / \mathrm{ml})$ & 2.4 & & 4.4 & & 13.5 & 35.5 & 13.0 & 3.2 & 9.1 \\
\hline & cortisol $(\mu \mathrm{g} / \mathrm{d} l)$ & 12.7 & 12.8 & 17.1 & 22.5 & 10.3 & 26.6 & 27.1 & 28.4 & 26.5 \\
\hline & IRG $(\mathrm{pg} / \mathrm{ml})$ & 123 & 93 & 116 & 141 & 339 & 243 & 19.4 & 172 & 114 \\
\hline \multirow[t]{3}{*}{ AT } & BS (mg/dl) & 67 & 69 & 70 & 80 & 76 & 63 & 60 & 63 & \\
\hline & $\operatorname{IRI}(\mu \mathrm{U} / \mathrm{mI})$ & 3 & 4 & 10 & 26 & 26 & 12 & 10 & 4 & \\
\hline & IRG $(\mathrm{pg} / \mathrm{ml})$ & 192 & 102 & 277 & 449 & 437 & 443 & 359 & 244 & \\
\hline
\end{tabular}

Fasting blood sugar and IRI concentrations except for those obtained on the day following admission were all within normal 
Table 4. Urinary output of catecholamine for 2-hr period before and after injection of insulin.

\begin{tabular}{lcc} 
& \multicolumn{3}{c}{ urinary content $(\mu \mathrm{g} / 2 \mathrm{hr})$} \\
\hline & adrenaline & noradrenaline \\
before & 1.6 & 10.4 \\
after & 7.7 & 9.5 \\
\hline
\end{tabular}

range. No additional apparent hypoglycemic episode was observed in hospital. Because of these clinical course and biochemical findings, factitious hypoglycemia was suspected. Blood specimens obtained on the day subsequent to her admission and the 30th hospital day had been frozen, allowing us to determine sulfonylurea content. Results showed sulfonylurea concentration of $13.3 \mathrm{mg} / \mathrm{dl}$ equivalent to tolbutamide in the former sample and none in the latter. On the basis of this result, the patient's belongings had been searched during her absence and a medical social worker had interviewed her several times, but these were not rewarded. When informed of our findings the patient's denial that she took sulfonylurea agents was unabated.

She was discharged to psychiatric care.

\section{DISCUSSION}

We have described a twenty-three year old nurse who presented with symptoms and laboratory evidence suggestive of spontaneous hypoglycemia. The case fulfilled all the criteria of Whipple's triad, and an islet-cell tumor was initially suspected. Furthermore, the low fasting blood sugar level associated with the high IRI in the sample obtained on the second hospital day, as well as the result of the prolonged fasting gave us additional data suggesting the presence of insulinoma. However, the responses to glucagon and tolbutamide were not typical of insulinoma. Rather, a poor response of plasma IRI to tolbutamide was observed, as demonstrated by Walfish et al. ${ }^{12)}$ in their case with sulfonylureainduced hypoglycemia. These findings, together with suppression of C-peptide secre- tion during insulin-induced hypoglycemia might negate the possibility of insulinoma, but suggest other etiologies for this case's disorder, the most likelihood of factitious hypoglycemia.

Biochemically, there is little to differentiate the hypoglycemia induced by sulfonylurea agents from that produced by an insulinoma. The most reliable means of documenting inappropriate insulin release in a patient with an insulinoma has been during a supervised fast. This is due to the fact that dependency of insulin secretion on blood sugar levels is either completely or partially lost in insulinomas. ${ }^{10)}$ The same is true in the mechanism for low glucose/insulin ratio in this disease, which was advocated by Shatney et al. ${ }^{8}$ as a diagnostic index. The autonomy of insulin secretion in insulinomas might be demonstrated more easily under the circumstance of insulin-induced hypoglycemia. However, this kind of suppression test has not been fully established until recently, because of the difficulty in discriminating endogenous human insulin from bovine or porcine insulin injected exogenously for lowering a blood sugar level. Since C-peptide is released in equimolar amounts during insulin secretion and can be measured without interference with the exogenous insulin, the determination of peripheral C-peptide levels can provide a new way for assessing the beta cell function under the circumstances. Following the injection of insulin, healthy subjects suppress CPR levels to $40 \%$ of the basal when the plasma glucose falls below $40 \mathrm{mg} / \mathrm{dl}$. In contrast with the suppression of plasma CPR in these subjects, all but one $^{13)}$ patient with insulinoma challenged by this test showed small suppression of plasma GPR level even though the blood glucose fell adequately. Although not a decisive point in differential diagnosis of various etiologies of hypoglycemia, inadequate suppression of plasma GPR under the circumstances of insulin-induced hypoglycemia might rule out the presence of insulinoma but suggest us to consider other causes for the hypoglycemia. If an occupa- 
tion of our patient is taken into account, factitious hypoglycemia is highly probable because the high incidence of this disorder have been reported among the paramedical personell. ${ }^{3)}$ In insulin-induced factitious hypoglycemia insulin-binding antibodies and/or low GPR with hyperinsulinism should be presented. ${ }^{14,15)}$ Since no apparent discrepancy between the concentration of IRI and CPR in blood was demonstrated in our case, it was unlikely that the hypoglycemia was due to the self-administration of insulin though insulin-binding antibodies were not investigated. In the present case hypoglycemia was most likely due to the surreptitious administration of potent oral sulfonylurea. The diagnosis was confirmed by direct serum assay for sulfonylurea. Because of the patient's adamant denial of taking hypoglycemic drugs, one may argue against the diagnosis of factitious hypoglycemia induced by self-administration of sulfonylurea though a large amount of the agent was detected in the blood sample. But, the assay employed in this study was highly specific for sulfonylurea, no detectable amount of sulfonylurea was demonstrated in the blood sample which was taken in an euglycemic state and not any hypoglycemic episode was encountered after keeping a close eye on her; these facts are additional circumstantial evidences for supporting the notion that her hypoglycemia was the factitious one, most lilely due to taking the sulfonylurea derivatives surreptitiously.

According to Jordan et al. ${ }^{3)}$ four cases out of eight with sulfonylurea-induced factitious hypoglycemia in literature underwent a needless laparotomy and the incidence of this dicorder is increasing and approaching to that of insulinoma. These facts suggest that the physician must give more serious consideration to factitious hypoglycemia. If the patient is or has been medically employed like this case, the factitious hypoglycemia becomes more likely. It would seem reasonable, therefore, to recommed that blood determinations of sulfonylurea agents should be performed prior to exploratory laparotomy, especially in paramedical personell when the hypoglycemia of an unknown etiology was encountered.

ACKNOWLEDGEMENTS: The authors were indebted to Höchst Japan for measuring sulfonylurea content in blood.

\section{REFERENCES}

1) Duncan GG, Jenson W, Eberly RJ: Factitious hypoglycemia due to chlorpropamide. Report of a case, with clinical similarity to an istet cell tumor of the pancreas. J. A. M. A. $175:$ 904, 1961.

2) Service FJ, Palumbo PJ: Factitious hypoglycemia. Three cases diagnosed on the basis of insulin antibodies. Arch. Intern. Med. $134: 336,1974$.

3) Jordan RM, Kammer H, Riddle MR: Sulfonylurea-induced factitious hypoglycemia. A growing problem. Arch. Intern. Med. 137 : 390, 1977.

4) Horwitz DL, Rubenstein AH, Reynolds C, et al: Prolonged suppression of insulin release by insulininduced hypoglycemia. Demonstration by C-peptide assay. Horm. Metab. Res., $7:$ 449, 1975.

5) Shima K, Morishita S, Sawazaki N, et al: Suppressibility of function of pancreetic beta cells evaluated by changes in plasma G-peptide immunoreactivity after insulin injection. J Japan Diab Soc 19: 498, 1976. (Japanese)

6) Shima K, Tanaka R, Morishita S, et al : Studies on the etiology of "brittle diabetes". Relationship between diabetic instability and insulinogenic reserve. Diabetes 26: 717, 1977.

7) Spingler $\mathrm{H}$ : über eine Möglichkeit zur colorimetrischen Bestimmung von N-(4methyl-Benzolsulfonyl)-N'-butyl-Harnstoff in Serum. Klin Wsch 35: 533, 1957.

8) Shatney $\mathrm{CH}$, Grage $\mathrm{TB}$ : Diagnostic and surgical aspects of insulinoma. A review of twenty-seven cases. Amer J Surg 127: 174, 1974.

9) Laurent J, Debry G, Floquet J: Hypoglycemic tumor. Excerpta Medica, Amsterdam p. 39, 1971.

10) Turner RC, Harris E: Diagnosis of insulinomas by suppression test. Lancet 2 : 188, 1974. 
Factitious Hypoglycemia

11) Service FJ, Horwitz DL, Kuzuya $H$, et al: Diagnosis of insulinomas by C-peptide measurement during hypoglycemia induced by insulin infusion. The Endocrine Society 58th Annual Meeting Program and Abstract, 66: 1976 (Abstract).

12) Walfish PG, Kashyap RP, Greenstein $S$ : Sulfonylurea-induced factitious hypoglycemia in a nondiabetic nurse. Can Med J 112: 71, 1975.

13) Rayfield EJ, Pulini M, Golub A, et al: Nonautonomous function of a pancreatic insuli-

noma. J Clin Endocrinol Metab 43: 1307, 1976.

14) Berkowitz S, Parrish JE, Field JB: Factitious hypoglycemia, why not diagnose before laparotomy? Amer J Med 51: 669, 1971.

15) Couropmitree C, Freinhel N, Nagel JC, et al: Plasma C-peptide and diagnosis of factitious hyperinsulinism. Study of an insulin-dependent diabetic patient with "spontaneous" hypoglycemia. Ann Int Med 82: 201, 1975. 